\title{
LAW STUDENTS, DISCOURSE COMMUNITIES, AND REGRESSION: A STUDY OF THE WRITING PERFORMANCE OF FIRST-YEAR LAW STUDENTS
}

\author{
Geofrey Crago
}

In 1984, at the First Annual Conference on Legal Writing held at the University of Puget Sound, Dr. Joseph Williams of the University of Chicago ${ }^{1}$ discussed the problems of teaching writing skills to first year law students. Drawing on personal experience supported by the work of learning theorists and cognitive psychologists, he concluded that such an enterprise is not particularly effective. New law students, he stated, are intellectually preoccupied with mastering the concepts and terms of a new discipline; furthermore, the anxiety caused by a new environment causes resistance, even hostility, to the demands posed by an introductory writing course. For these reasons, the writing performance of first-year law students deteriorates and only when they begin to internalize their intellectual domain does their writing return to its previous level of quality. As a consequence, Williams argued, writing instruction should be postponed until the second or even third year of law school.

This argument has obvious pedagogical and administrative consequences for legal writing instructors. However, the underlying issue-the transferrability of writing skills from one discipline to another-ought to concern those of us who, in our technical writing courses, teach students who wish to become professional technical writers, editors, and consultants. Their work will involve a wide range of subjects and disciplines, in which they cannot hope to be expert. If Williams is correct-if writing skill is so closely dependent on substantive knowledge and competence-then our enterprise is unlikely to prosper.

In this paper I do not wish to refute Williams' argument. Taken broadly, it squares with what we know about student writers when they are struggling with new and difficult material; problems with content are usually reflected in organization, and often cause problems in word use and syntax. However, his model requires refinement to describe the writing experience of first-year law students who, in most cases, are writers with considerable 
academic writing experience. On the basis of the studies described in this paper, I will argue that although some law students create more errors in their initial legal assignments than in their undergraduate papers, some maintain their earlier standard, and that the general deterioration in writing that Williams posits as typical is, in fact, rare. I will also suggest that some of the recent work on discourse communities may be helpful to teachers of legal and technical writing.

Williams' argument is concerned with the adjustment of writers to a new discipline. Because of the influence it may have on their transition into legal academia, a brief description of the legal writing program at the University of Calgary may therefore be helpful. All law students (a class of about sixty-five) are required to take the legal writing and communication course at the beginning of their first year. The course is typically allotted seven weeks. Two instructors, one from Law and one from Communications Studies, ${ }^{2}$ teach the main lectures; additional Law professors are responsible for further instruction in small tutorial groups.

Despite its brevity, the course has several purposes: to acquaint students with new genres-the case comment and legal memorandum, as well as oral advocacy; to familiarize them with stylistic and organizational conventions of legal writing; to provide remedial tutoring for those students referred by their small group instructors. In addition, though less obviously, the course acquaints students, both explicitly and implicitly, with the standards and conventions of their new discourse community and begins the process of initiation. To achieve these purposes, the course requires students to write two assignments-a case comment and a legal memo.

The case comment is a uniquely legal genre. Outside law schools, it is frequently found in law journals. It is therefore scholarly, but has a practical purpose: it informs the legal community of developments and issues in case law. As its name implies, the case comment is more than a careful summary of past and present judicial thought on a particular legal problem: it is a comment, an evaluation. ${ }^{3}$ To write a competent case comment students must create a thesis which addresses both the quality of a judgement and its impact on social policy. They must also strike an appropriate balance between exposition and argument, a task made more difficult by an unfamiliar audience, a new academic discipline, a new vocabulary, and a strict length limit-all features of adjusting to the conventions of a new discourse community. Although many of the case comment's demands are novel, its form is familiar to most students; it is essentially an essay, and like most academic essays it emphasises coherence and tight structure. 
The Memorandum of Law, on the other hand, is more closely related in form to the short formal report. In comparison to the case comment, the legal memo is not strictly linear. A series of short answers to the key questions posed by a legal problem are followed by an extended discussion which "presents the authorities on which the conclusion rests." discussion is followed by a conclusion and recommendations section which also presents some of the same material at an intermediate level of detail. As in a formal report, these sections are independent, signalled by headings, and permit easy reference for a busy reader. Although the analysis and research required for the memo assignment are comparable to that of the case comment, the form of the memo may be less familiar to students. An informal survey of this year's class indicated that fewer than twenty percent had experience in writing formal reports.

Neither of these assignments emphasizes research skills. Students must discuss a primary case, and are directed to a small number of secondary cases which bear on it. This simplicity might seem to make their task easier. However, although the assignments do not permit extensive research, they require careful analysis, very close reading from primary texts, and strong argument. Students accustomed to dependence on secondary texts may find these features of the assignments difficult and unfamiliar. The authorial role demanded by these assignments may also be stressful and novel. Although the students lack any detailed knowledge of law, they must be able to evaluate the quality of judicial reasoning they encounter in their cases, and assess the usefulness of the secondary cases to their case or fact situation. Both the case comment and memo require students to create a thesis and to support it from the limited texts available. Using Hesse's matrix of insiders and outsiders to describe a rhetorical situation, ${ }^{6}$ we could say that students are required to write with the authority of insiders, to an audience of formidably knowledgeable insiders, when their lack of content mastery makes them very much outsiders. To compound their difficulties, students must deal with a strict length limit-1200 words for the case comment and 1500 for the memo. Most find such a limit difficult, and some encounter structural problems in trying to meet it, often making a strategic sacrifice of one section in a desperate attempt to get in under the limit. ${ }^{7}$ On a number of levels, then, the legal writing assignments are challenging to new students.

Williams asserts that for just these reasons, and also because students are still grappling with a vast new cognitive domain, writing performance must inevitably decline, and intervention is pointless. Despite the logic of his position, I undertook a preliminary study because my own observations did not fully support his contentions. The quality of the legal writing assignments 
I had read varied greatly. Some had certainly exhibited the sort of structural and editorial chaos that Williams predicts, but many demonstrated much more limited difficulties, and some were both coherent and polished, obviously the work of competent writers.

The observations of both law professors and students confirmed these impressions. The small-group instructors who mark assignments usually refer fewer than fifteen percent of the first-year class for serious problems: as the same instructors are regular faculty and mark assignments in credit courses, the low referral rate indicates that the initial non-credit assignments generally meet an entrance standard of performance satisfactory to the Faculty of Law. In tutorial sessions, students often indicate to me that at least some of their writing problems are not new, but habitual; some also comment that they are not accustomed to having their writing scrutinized so closely. These comments suggest that at least some of the writing problems that may lead to a referral are not new, and that the writing standard and conventions may have changed more than the students' performance.

I was sufficiently intrigued by the discrepancies between Williams' argument and my own observations to conduct a preliminary study. My major purpose was simply to determine how often and how greatly the writing performance of first-year law students declined. A small group of students volunteered to give me samples of recent writing as well as one of their legal writing assignments. I than marked these using a detailed code, without weighting any group of errors, and obtained error-frequency figures.

The code used was initially developed for marking the Alberta Universities Writing Competence Test (see Appendix I) and is one with which I am well acquainted. It is a detailed analytical code which classifies errors into seven categories: content, structure, paragraphs, sentences, grammar, word use, and spelling/punctuation. The method of marking I employed was strictly analytical and error-driven. Although this method is unlikely to reflect the overall quality of a text, and does not represent my normal appraisal of an assignment's strengths and weaknesses, it does offer a reasonably detailed and objective manner of detecting, recording and comparing patterns of error, which an examination of Williams' argument seems to require. Nonetheless, no marking system is perfectly objective, and this problem is exaggerated when the marker is an outsider who is unfamiliar with the writing conventions of certain disciplines. When marking under these circumstances, I therefore adapted the audience role which I employ in my technical writing course or in consulting work, that of the (I hope) intelligent non-expert. Although this approach allows consistency, it may still reflect an outsider's approach to certain conventions of style, organization, 
and audience within a particular discipline and may, therefore, cause insensitive marking.

Despite these qualifications, the results of the first survey, shown in Table I below, were intriguirg. From Williams' theory we would expect the law assignments to be considerably more error-ridden than the corresponding undergraduate assignments. Such was not the case. None of the students surveyed showed the sort of general deterioration that Williams would predict. As the table indicates, some students created relatively more errors in their legal writing assignments, but some changed very little, and two created fewer errors. Even students with a relatively high error frequency in their undergraduate paper did not regress greatly. In some instances the increase in errors was less dramatic than indicated, because the samples were not equivalent. For example, Andre more than doubled his error frequency. However, his prior sample was a published article which had obviously received more attention and time in its preparation than his case comment. Of more interest were the cases-the majority-where the error frequency remained roughly constant or decreased.

TABLE I

Preliminary Survey: Error-Frequency Comparison

Student

Discipline

Undergrad. Ass't

Law Ass't

1. Andre

Psychology

$.2: 100$

$.4: 100$

2. Rama

English

$.6: 100$

$.3: 100$

3. Laurence

Poli. Sci.

$.9: 100$

$.8: 100$

4. Ann

Marketing

$1.0: 100$

$1.0: 100$

5. Cathy

English

$1.8: 100$

$1.8: 100$

6. Walter

English

$1.9: 100$

$2.1: 100$

7. Don

Psychology

$2.9: 100$

$3.3: 100$

Although the preliminary study did suggest that law students do not always regress to the extent that Williams' theory would lead us to expect, the results required confirmation and the design needed refinement. A second study was therefore conducted in 1987. Once again I collected writing samples from the first-year class. However, my aims were more specific: I wished to create the greatest possible contrast between undergraduate and law school assignments and to investigate the possible influence of undergraduate writing conventions. Following Williams' assertion that students write best when they are expert in a particular universe of discourse, I obtained recent undergraduate papers written for students' majors. To 
further reinforce the contrast between writing samples, I collected only case comments, assuming that the first law assignment should be the weaker of the two and should best indicate which legal writing conventions cause the most difficulty. I hoped that these refinements might also confirm or deny the possibility that students' former disciplines influence their ability to swiftly adapt to the demands of legal writing assignments. It should be noted that the major features of the legal writing program remained in place; the instructional philosophy, assignments, marking standards and referral system were unchanged.

The results of the second study are shown in the table below.

\section{TABLE II}

Second Survey: Error-Frequency Comparison

Student

1. Kelly

2. Debby

3. Diane

4. Jane

5. Janice

6. Greg

7. Barbara

8. Lynne
Discipline

Geology

Biology

Philosophy

English

Poli. Sci.

Poli. Sci.

Philosophy

Sociology
Undergrad. Ass't

Case Comment

$.4: 100$

$2.3: 100$

$.4: 100$

$.9: 100$

$1.5: 100$

$.9: 100$

$.8: 100$

$1.0: 100$

$1.4: 100$

$2.6: 100$

$1.9: 100$

$25: 100$

$2.5: 100$
$3.0: 100$

$2.1: 100$

$2.1: 100$

At first glance, the frequency of errors seems to confirm Williams' position more strongly than the preliminary study's findings. Of the eight students who participated, five committed errors more frequently in their case comment than in recent undergraduate writing. Closer analysis modifies this impression. For example, the two students with a science major might seem to be the most correct undergraduate writers and to have deteriorated the most in their case comments. However, their undergraduate samples were both major research papers, one of which was later to be published; naturally these had received greater attention than the subsequent case comments. Nonetheless, the increase in frequency of errors must be admitted. Both students suffered from organizational problems in their case comment, especially in paragraph coherence. The next student who showed an increase in error frequency had majored in English. Her difficulties were reflected mainly in word use, specifically wordiness and over-compression. These problems illustrate Williams' argument well, since they suggest problems adjusting to new vocabulary, new concepts, and a new audience. Despite the 
marked increase in word use errors, the frequency of other errors was very nearly equal, thus suggesting that writing performance may be affected adversely, but very specifically, by the transition to a new discipline.

The two students vith a Political Science background both created relatively more errors, but their patterns of error differ. The first student, Janice, wrote a Political Science paper with a fairly even distribution of errors in all categories but content and structure; her case comment showed a greater proportion of sentence and word use problems, especially wordiness. On the other hand, Greg's Political Science paper was very weak in structure and paragraphing; his case comment was structurally superior, slightly weaker in sentences, and flawed by a stylistic affectation-the omission of the definite article. This problem, although minor in itself, shows the difficulty of acquiring stylistic judgement. More importantly, Greg's performance suggests that although the case comment is a novel genre for entering law students, its restrictions may assist students who have difficulty with more open and flexible forms.

The fact that five of the eight students in the second study created more errors in their initial legal writing assignment certainly supports Williams' argument, but only to a limited extent. Their writing tended to deteriorate in one or two categories, rather than globally, and no one category predominated. A more detailed study might reveal that the areas in which they deteriorated were indeed their typical areas of difficulty. Despite the adjustment to a new discipline and new writing conventions, they seemed to retain most of their prior skill in writing. Perhaps more important, students referred to me for additional instruction were able to improve their performance. Despite Williams' contention that improvement occurs only gradually, after students become familiar with their new cognitive domain, most students referred to me for sub-standard performance in their legal writing assignments redeem themselves after one revision. Their learning ability is not impaired to the extent we would expect.

The students who created relatively fewer errors pose a more interesting analytical problem. In the case of the first student, Diane, the major difference lay in fewer syntax and punctuation faults. A major decrease in sentence errors and a slight improvement in spelling also reduced the error frequency of the case comment for the second student, Barbara. The possibility that a decrease in editoriat problems explains the shift is only partly supported by the third student, Lynne. In her case, an absence of larger structural problems and a reduction in word use errors caused a decline in error frequency. 
What, if anything, do these numbers and observations prove? The statistically sophisticated reader may well comment that in the strictest sense of the word they prove nothing. However, despite the weaknesses and limits of the studies' design, the data may have some descriptive importance. Several points are confirmed by both studies:

1. Not all students decline in writing performance (as measured by frequency of error) upon entering law school.

2. Those who do create more errors tend to do so in one or two categories rather than globally.

3. Relative freedom from error in undergraduate writing does not seem to predict an increase or decrease in errors on legal writing assignments, nor is there a typical ratio between the error frequencies of the two sets of writing. 4. Similarly, there does not seem to be any means of predicting whether an increase in errors will be due to organizational or editorial problems.

The research to this point, though provocative, is hardly conclusive. What does seem likely is that the loss and reacquisition of writing skills is more complex than Williams suggests. However, a number of important issues still require more thorough investigation:

1. the influence of undergraduate discourse conventions

2. the process of reacquisition of writing skills

3. the influence and efficacy of mediation and instruction

4. the significance of students' attitudes to writing and to themselves as writers.

To address at least some of these questions, I am launching a third phase to the study described in this article. This will involve obtaining a larger number of assignments from a larger group of volunteers, a similar process of marking and interpretation, and, in addition, a series of formal interviews and questionnaires.

My findings are not yet sufficiently detailed or conclusive to provide a model of the acquisition of writing competence in a new discipline. To this point, the findings are encouraging; they indicate that most students are able to retain a good deal of their writing ability and to apply it to the demands and conventions of an unfamiliar discourse community. However, as yet we know little about the effect of students' previous writing experience and their attitude to writing on their transition to new discourse conventions. Pending more detailed and authoritative findings, I would like to make a strong plea for the teaching of a comprehensive communications theory in our technical writing classes and for the promotion of writing assignments which assist our 
students in making the transition from outsiders to insiders and in identifying the conventions of unfamiliar discourse communities. I stress the importance of theory because I doubt that students unequipped with theory will be able to notice or interpret these conventions. Because I am best acquainted with classical rhetorical theory, I am naturally partial to it. However, other theories will do equally well, as long as they assist students in detecting and analyzing discourse conventions and provide students with a coherent set of principles or heuristics for appraising their own writing performance.

In our teaching, I suggest that we promote the widest possible exposure to a wide variety of conventions. We should draw on examples from different technical disciplines, written for different rhetorical situations, and use these samples to demonstrate the variety of discourse conventions. By doing so, we may be able to disabuse our students of the notion that writing can be simply appraised as correct or incorrect. The sort of writing assignments described by Hesse $^{8}$ involving different authorial roles also seem likely to increase flexibility and acuity. Perhaps, especially in senior courses, we should also provide our students with examples of the types of technical discourse that they may expect to revise and edit, so that they may begin to acquire expertise in identifying and working within unfamiliar conventions.

The studies described in this paper arose in response to Williams' presentation. Not surprisingly, they suggest the need for some modifications to his argument. These, however, are less important than the soundness of his central thesis--that the transition to a new academic discipline with its own discourse conventions is often difficult and traumatic even for highly competent students. Although he is specifically concerned with the transition to legal training and writing, the problem he raises is one which should occupy our attention in technical, business, and professional writing classes as well.

\section{NOTES}

${ }^{1}$ Author of Style: Ten Lessons in Clarity and Grace among other works.

2I have taught in this position since the formal inception of the program in 1981.

${ }^{3}$ Law 408 Materials (unpublished, revised 1988), p. 11-21.

${ }^{4}$ Henry Weihofen, Legal Writing Style (West, 2nd edition 1980), p. 230. 
${ }^{5}$ Law 408 workshop, September 28,1988 ; this point was confirmed in several subsequent exchanges with students.

"Douglas Hesse, "Insiders and Outsiders: A Writing Course Heuristic," in The Writing Instructor, Winter 1988, p. 84.

${ }^{7}$ Interview with Ingrid Ektvedt, October 3, 1988.

${ }^{8}$ Hesse, p. 87.

Geoffrey Cragg teaches writing courses at the University of Calgary. 


\section{APPENDIX I}

Marking Code

(December 1981)

\section{Content $\mathbf{C}$}

1. Too short

2 Lacks substance; vague waffling or repetitious

3. Logical flaws

4. Off topic

5. Inadequate or inappropriate sense of audience.

\section{Structure/Organization ST}

1. No or unclear thesis

2. Poor introduction

3. Poor middle development

4. Passage not clearly related to

5. Poor transitions

6. Poor conclusions

\section{Paragraphing PA}

1. No new paragraph needed

2. New paragraph needed

3. Poor development; elliptical paragraph; omission of logical steps

4. Poor unit or order

5. Poor coherence or transition

\section{Sentence Errors SE}

1. Fragment

2. Comma splice

3. Fused sentence

4. Overloaded sentence

5. Mixed construction

6. Parallelism

7. Dangling modifier

8. Misplacement

9. Shift of number or person

10. Shift of tense, mood, voice

11. Omission

12. Lack of variety

13. Unclear logical connections; coordination of logical unequals; illogical predication

\section{Grammar GR}

1. Noun marking (articles, preposition, plurals, idioms)

2. Syntax (non-English word order)

3. Usage

4. Case

5. Verb Form

6. Faulty reference

7. Subject-verb agreement

8. Wrong part of speech; infinitive/gerund confusions

VI. Words W

1. Wrong word

2. Too many words

3. Excessive compression

4. Repetitious diction

5. Inappropriate diction (jargon, cliche, colloquialism or inappropriate metaphor)

\section{Spelling SPP}

1. Commonly confused pairs

2. Apostrophe

3. Others

4. Proofreading

\section{Punctuation PU}

1. Comma

2. Semi-colon

3. Colon

4. Dash

5. Parenthesis

6. Quotation marks

7. Hyphen

8. Question mark

9. Exclamation mark

10. Period

11. No punctuation needed 